\title{
Exercise training with dietary counselling increases mitochondrial chaperone expression in middle-aged subjects with impaired glucose tolerance
}

\author{
Mika Venojärvi*1,2,3, Sirkka Aunola3 ${ }^{3}$ Raivo Puhke4, Jukka Marniemi3, \\ Helena Hämäläinen ${ }^{5}$, Jukka-Pekka Halonen ${ }^{5}$, Jaana Lindström6, \\ Merja Rastas ${ }^{7}$, Kirsti Hällsten ${ }^{8}$, Pirjo Nuutila ${ }^{8}$, Osmo Hänninen ${ }^{1}$ and \\ Mustafa Atalay ${ }^{1}$
}

Address: ${ }^{1}$ Institute of Biomedicine, Physiology, University of Kuopio, POB 1627, FI-70211, Kuopio, Finland, ${ }^{2}$ Medical Laboratory Technology, Turku University of Applied Sciences, Ruiskatu 8, FI-20721, Turku, Finland, ${ }^{3}$ Department of Health and Functional Capacity, Laboratory for Population Research, National Public Health Institute, Turku, Finland, ${ }^{4}$ Institute of Exercise Biology and Physiotherapy, University of Tartu, Tartu, Estonia, ${ }^{5}$ Research Department, Social Insurance Institution, Turku, Finland, ${ }^{6}$ Department of Health Promotion and Chronic Disease Prevention, Diabetes Unit, National Public Health Institute, Helsinki, Finland, ${ }^{7}$ Department of Health Promotion and Chronic Disease Prevention, Nutrition Unit, National Public Health Institute, Helsinki, Finland and ${ }^{8}$ Turku PET Centre, University of Turku, Turku, Finland

Email: Mika Venojärvi* - mika.venojarvi@turkuamk.fi; Sirkka Aunola - sirkka.aunola@ktl.fi; Raivo Puhke - raivo.puhke@ut.ee; Jukka Marniemi - jukka.marniemi@ktl.fi; Helena Hämäläinen - helena.hamalainen@kela.fi; Jukka-Pekka Halonen - jukkapekka.halonen@kela.fi; Jaana Lindström - jaana.lindstrom@ktl.fi; Merja Rastas - merja.rastas@ktl.fi; Kirsti Hällsten - kirlar@utu.fi; Pirjo Nuutila - pirjo.nuutila@utu.fi; Osmo Hänninen - osmo.hanninen@uku.fi; Mustafa Atalay - mustafa.atalay@uku.fi

* Corresponding author

Published: 27 March 2008

BMC Endocrine Disorders 2008, 8:3 doi:10.1/86/1472-6823-8-3

This article is available from: http://www.biomedcentral.com/l472-6823/8/3

(c) 2008 Venojärvi et al; licensee BioMed Central Ltd.

This is an Open Access article distributed under the terms of the Creative Commons Attribution License (http://creativecommons.org/licenses/by/2.0), which permits unrestricted use, distribution, and reproduction in any medium, provided the original work is properly cited.

\begin{abstract}
Background: Insulin resistance and diabetes are associated with increased oxidative stress and impairment of cellular defence systems. Our purpose was to investigate the interaction between glucose metabolism, antioxidative capacity and heat shock protein (HSP) defence in different skeletal muscle phenotypes among middle-aged obese subjects during a long-term exercise and dietary intervention. As a sub-study of the Finnish Diabetes Prevention Study (DPS), 22 persons with impaired glucose tolerance (IGT) taking part in the intervention volunteered to give samples from the vastus lateralis muscle. Subjects were divided into two sub-groups (IGTslow and IGTfast) on the basis of their baseline myosin heavy chain profile. Glucose metabolism, oxidative stress and HSP expressions were measured before and after the 2-year intervention.
\end{abstract}

Results: Exercise training, combined with dietary counselling, increased the expression of mitochondrial chaperones HSP60 and glucose-regulated protein 75 (GRP75) in the vastus lateralis muscle in the IGTslow group and that of HSP60 in the IGTfast group. In cytoplasmic chaperones HSP72 or HSP90 no changes took place. In the IGTslow group, a significant positive correlation between the increased muscle content of HSP60 and the oxygen radical absorbing capacity values and, in the IGTfast group, between the improved $\mathrm{VO}_{2 \max }$ value and the increased protein expression of GRP75 were found. Serum uric acid concentrations decreased in both sub-groups and serum protein carbonyl concentrations decreased in the IGTfast group.

Conclusion: The 2-year intervention up-regulated mitochondrial HSP expressions in middle-aged subjects with impaired glucose tolerance. These improvements, however, were not correlated directly with enhanced glucose tolerance. 


\section{Background}

Diabetes and its complications are increasing as major causes of mortality and morbidity in the developed countries [1]. Insulin resistance and diabetes are associated with increased oxidative stresmpaired cellular defence systems [2-4]. We have recently shown in rats that streptozotocin-induced diabetes (SID) increase oxidative stress and resulted in impaired heat shock protein (HSP) responses in liver and skeletal muscle tissue [2]. HSPs are a family of proteins that promote cell survival after a wide variety of environmental stresses. The most widely studied HSP family is the 70-kDA family, which contains the constitutive HSP73 and inducible HSP72 forms. HSP72 plays a central role in protein synthesis, translocation, folding and assembly/disassembly of multimetric protein complexes as molecular chaperones [5]. In type 2 diabetic subjects, insulin resistance correlates with decreased expression of HSP72 in skeletal muscle [6]. HSP60 and glucose-regulated protein 75 (GRP75) are located in the mitochondria, where they are involved in the trafficking and processing of nuclear encoded peptides [7,8]. HSP90 is expressed in the cytosol, nucleus and endoplasmic reticulum [9] and has several physiological roles, including mediating tyrosine kinase receptor maturation and protein kinase B (PKB/AKT) stability, an important activator of glucose transports systems $[9,10]$. A number of studies have shown the expression of HSPs to vary depending on the muscle fibre type [11-13].

Oxidative stress, in which the increased production of reactive oxygen species (ROS) overwhelms endogenous antioxidant protection, may result in biomolecular damage. However, at lower concentrations, ROS also serve as secondary messengers, regulating cellular functions and adaptations. ROS have important role in signal transduction pathways involved in cell growt $h$, proliferation and differentiation, as the mitogen-activated protein kinase (MAPK) pathways [14] Oxidative stress may have an important role in the pathophysiology of insulin resistance and diabetes and its complications through increased oxidative damage, inflammation and apoptosis [15-17]. Recent in vitro and in vivo studies have also shown that the antioxidant supplementation suppresses ROS production and improves glucose tolerance and insulin sensitivity [18].

Strategies to decrease oxidative stress and to modulate HSP expression may have important implications for reducing insulin resistance and increasing the protection against diabetes and its complications. Very little is known about the effects of exercise and dietary interventions on the antioxidant defence and protection of HSPs in humans with impaired glucose metabolism [6,19], although information is available in different animal models [2]. Our purpose was to study whether a 2-year exercise and dietary intervention improves the antioxidative capacity and HSP defence of different skeletal muscle fibre phenotypes in middle-aged obese subjects with impaired glucose tolerance. Furthermore, we aimed to investigate the association of tissue defences with improved glucose metabolism.

\section{Methods}

This study is a sub-study of the Finnish Diabetes Prevention Study (DPS), which has been described in detail elsewhere $[20,21]$. This sub-study was carried out in Turku with 22 subjects who volunteered to give muscle samples. The intervention started with intensive dietary counselling [20,22]. After 6 months, a supervised, progressive and individually tailored circuit-type resistance training program started. Blood samples for metabolic indices were taken at baseline and after 2 years and maximal exercise test and muscle sampling (with no heavy exercising during the preceding 2 days) were performed at 6 months and after 2 years. In skeletal muscle glucose metabolism, the greatest changes due to the dietary counselling were assumed to have occurred by 6 months. While this gives a good view of the changes in the regulation of the skeletal muscle metabolism induced by exercise, it does not allow us to distinguish the effects of either exercise or dietary counselling separately.

\section{Subjects}

A total of 110 obese subjects with impaired glucose tolerance (IGT), were randomized to an intervention or a control group, based on two oral glucose tolerance tests. IGT was defined as 2-hour plasma glucose concentration from 7.8 to $11.0 \mathrm{mmol} / \mathrm{l}$ in oral glucose tolerance test (OGTT) with an intake of $75 \mathrm{~g}$ glucose in subjects whose fasting plasma glucose concentration was less than $7.8 \mathrm{mmol} / \mathrm{l}$ [23]. The test was repeated for subjects showing abnormal values, and the mean of the two 2-hour plasma glucose values was used as the inclusion criterion [20,22]. Twentytwo persons from the intervention group volunteered to give samples from their vastus lateralis muscle $(n=6$ for females, $\mathrm{n}=16$ for males). Depending on the proportion of muscle myosin heavy chain II (MHC II) fibres, the subjects were divided into IGTslow group (less than 55\% of MHC II fibres) or the IGTfast group [24]. The baseline characteristics of the subjects are shown in Table 1 . The Ethical Committee of the Hospital District of South-West Finland, Turku, Finland and the Ethical Committee of the Rehabilitation Research Centre of the Social Insurance Institution of Finland approved the protocol of this substudy. All subjects gave their written informed consent.

\section{Intervention}

The main goals of the intervention were as follows: 1) weight reduction of $5 \%$ or more, 2) less than $30 \%$ of the daily energy intake from fat, 3 ) less than $10 \%$ of the daily 
Table I: Baseline characteristics of the subjects with impaired glucose tolerance (IGT) divided into the slow and fast fibre type sub-groups.

\begin{tabular}{lcc}
\hline Characteristics & IGTslow & IGTfast \\
\hline$n=($ Female/Male) & $10(4 / 6)$ & $12(2 / 10)$ \\
& & \\
Age, yr & $58.5 \pm 2.0$ & $54.1 \pm 2.0$ \\
BMI (kg/m $\left.{ }^{2}\right)$ & $29.9 \pm 0.7$ & $29.9 \pm 0.7$ \\
Weight, kg & $86.9 \pm 2.8$ & $92.0 \pm 2.2$ \\
& & \\
Myosin heavy chain profile & & \\
MHC I, \% & $46.4 \pm 2.9$ & $30.6 \pm 1.0^{* * * *}$ \\
MHC Ila, \% & $36.9 \pm 3.5$ & $47.2 \pm 2.0^{* *}$ \\
MHC Ilx, \% & $16.7 \pm 3.3$ & $22.2 \pm 2.1$ \\
Blood chemistry & & \\
Fp-glucose, mmol/l & $6.0 \pm 0.2$ & $6.0 \pm 0.1$ \\
2h-glucose, mmol/l & $7.8 \pm 0.3$ & $7.5 \pm 0.5$ \\
Fs-insulin, $\mu \mathrm{U} / \mathrm{ml}$ & $12.9 \pm 1.0^{\mathrm{a}}$ & $19.5 \pm 2.7^{* \mathrm{~b}}$ \\
$2 \mathrm{~h}-$ insulin, $\mu \mathrm{U} / \mathrm{ml}$ & $72 \pm 13^{\mathrm{a}}$ & $117 \pm 35^{\mathrm{b}}$ \\
HbA $\mathrm{Ic}, \%$ & $5.7 \pm 0.1$ & $5.7 \pm 0.1$ \\
HOMA-IR & $3.5 \pm 0.3^{\mathrm{a}}$ & $5.2 \pm 0.7^{\mathrm{b}}$ \\
\hline
\end{tabular}

Data are given as means $\pm \mathrm{SE} ; * P<0.05 ; * * \mathrm{P}<0.01$, *** $\mathrm{P}<0.00 \mathrm{I}$ a $n$ $=9,{ }^{b} n=11$, Kruskall-Wallis test for difference between the groups.

energy intake from saturated fat, 4) fiber intake 15 grams per $1000 \mathrm{kcal}$ or more, and 5) moderately intense physical activity for 30 minutes per day or more. The implementation of the intervention program has been reported previously [20-22]. Briefly, the participants in the intervention group were given detailed and individualized counselling to achieve the set lifestyle goals. They had seven individual counselling sessions with the nutritionist during the first year and every three months thereafter. During the first 6 months, the intervention focused on dietary counselling, in order to allow the subjects to concentrate on changing their eating habits. The subjects were also individually encouraged by the nutritionist to increase their physical activity, and later on, to participate both in regular resistance training at gym and in aerobic exercise.

After 6 months, supervised exercise training twice a week was added to the intervention program [24]. The supervised training was progressive and individually designed, consisting mostly of strength and power training, interrupted by spinning exercises and aerobic gymnastic exercises. Power-type strength training at a fitness centre was performed as circuit training. Any physical activity lasting 30 min or longer was recorded by the participants. The subjects were advised to exercise with moderate-to-intensive effort for at least $30 \mathrm{~min}$ per session and three to four times a week. Eighteen of 22 participants attended to supervised training sessions at least once a week, but most of them twice or three times a week (range: 77-249 sessions) at a fitness centre. In addition, they trained by walking or other type of endurance exercises (range: 51-413 sessions). Only four participants did not attend regularly to the supervised training sessions, but they participated regularly in endurance type of sports or sports promoting muscular fitness or walking sessions (range: 105-554 sessions). Total amount of training varied from 105 to 584 sessions during the 2-year intervention period.

\section{Muscle biopsy}

A skeletal muscle biopsy was taken under resting condition (no heavy exercising during the preceding 2 days) from the vastus lateralis muscle under local anaesthesia (lidocaine $10 \mathrm{mg} / \mathrm{ml}$ ), using the 'semi-open' conchotomy technique [25]. Muscle samples were divided two separate pieces (approximately $40-60 \mathrm{mg}$ ) and immediately frozen in liquid nitrogen and stored at $-70^{\circ} \mathrm{C}$ until analyzed. Samples for biochemical analyses were melted in an ice bath, weighed and homogenized in 1:50 (w/v) of $1 \mathrm{M}$ Tris buffer $\mathrm{pH}$ adjusted to 7.5 in a manually operated all-glass homogenizer [26]. The enzyme activities[24] was measured immediately from the fresh homogenate and the rest of the homogenate were aliquots to five to six separate ependorf tubes and used for Western blot and ELISA analyses. The other piece of the muscle samples were used for the determination of myosin heavy chain profile.

\section{Exercise test and maximal oxygen uptake $\left(\mathrm{VO}_{2 \max }\right)$}

A 2-min incremental cycle ergometer test until volitional exhaustion or fatigue of the lower limbs was employed to measure the maximal oxygen uptake $\left(\mathrm{VO}_{2 \max }\right)$. The warmup loading was $30-40 \mathrm{~W}$ in women and $40-60 \mathrm{~W}$ in men, depending on the age, size and physical fitness of the subjects. Thereafter, work rate was increased every 2 nd min with equal increments $(10-25 \mathrm{~W})$ throughout the test. The increments were individually determined on the basis of the subject's physical fitness so that the maximum work rate would be reached in about 12-15 min [27]. Respiratory gas exchange was measured continuously by using a breath-by-breath method. $\mathrm{VO}_{2 \max }$ was recorded as the highest averaged value over $30 \mathrm{~s}$ at the work rate maximum [27].

\section{Assessment of dietary intake}

Nutrient intakes were assessed using a dietary analysis program developed by the National Public Health Institute [28]. At baseline and before the 24-month visit, the subjects were asked to complete a three-day food record $[29,30]$.

\section{Determination of myosin heavy chain profile}

The MHC isoform composition (MHC I, MHC IIa, MHC IIx) in muscle homogenate was determined by SDS-PAGE gel electrophoresis [31] by using a Bio-Rad Protean II Xi vertical slab gel system. The acrylamide and bis concentration were $4 \%$ in the stacking gel and $7.2 \%(\mathrm{w} / \mathrm{vol})$ in the separating gel, and the gel matrix included $30 \%$ glycerol. Electrophoresis lasted $24 \mathrm{~h}$ at $120 \mathrm{~V}$ and $+10^{\circ} \mathrm{C}$. The gels 
were silver stained (Bio-Rad Silver stain Plus Kit, Hercules, CA, USA) and analyzed using computer-based image analysis system and software (Image Master 1D Elite, Amersham Pharmacia Biotech, Uppsala, Sweden).

\section{Western blot assays}

Western blot assays were performed as described previously [2,32]. One-dimensional sodium dodecyl sulfate polyacrylamide $(10 \%)$ gel electrophoresis was done to separate proteins according to their molecular weight. The blots were incubated overnight at $+4^{\circ} \mathrm{C}$ with the following antibodies: anti-HSP60 (SPA-806), anti-HSP72 (SPA810), anti-GRP75 (SPA-825), anti-HSP-90 (SPA-835) (Stressgen, Victoria, BC, Canada) and anti-4-HNE (210767-R100) (Alexis Biochemical, San Diego, CA, USA). Horseradish peroxidase-conjugated immunoglobulins were used as secondary antibodies. Antibody binding was viewed by using an enhanced chemiluminescence method (NEN Life Science Products, Boston, MA, USA) and quantified by using the image analysis software (NIHImage, MD, USA). The results were normalized according to beta-actin (LabVision/NeoMarkers, Fremont, CA, USA) values. The protein concentration of homogenates was measured by using BCA method (Pierce, Rockford, IL, USA).

\section{Elisa assay for protein carbonyls of skeletal muscle and serum samples}

Protein carbonyls were measured with a slightly modified method according to Buss et al. [33] and Oksala et al. [34]. Briefly, protein derivation was carried out in $1.5 \mathrm{ml}$ reaction tubes. Forty-five $\mu$ l of dinitrophenylhydrazine (DNP) solution [35] was added to a $15 \mu$ sample. A final protein concentration was $1 \mathrm{mg} / \mathrm{ml}$. Absorbances were read with a $490 \mathrm{~nm}$ filter using a micro plate reader. The absorbance of the blank sample in PBS without protein was subtracted from all other absorbances. A seven-point standard curve of oxidized BSA (Sigma, Germany) was included with each plate [34].

\section{Blood chemistry}

Plasma glucose was analyzed enzymatically with hexokinase (Olympus Diagnostica, Hamburg, Germany) and serum insulin by radioimmunoassay (Pharmacia, Uppsala, Sweden). Hemoglobin A1c $\left(\mathrm{HbA}_{1 \mathrm{c}}\right)$ concentration was assayed by using the latex immunoagglutination inhibition method (Bayer Corporation, Elkhart, IN, USA: DCA, 2000 Reagent Kit). Insulin resistance was determined by the homeostasis model assessment for insulin resistance (HOMA-IR) as described by Matthews et al. [36]. Serum uric acid was determined photometrically by the hydroxylamine method [37]. Oxygen radical absorbing capacity (ORAC) was assayed by using a multi-well plate reader according to the methods described elsewhere [38,39]. Briefly, the antioxidant capacity of the samples was measured by the inhibition of the decrease of the fluorescence. For this purpose, fluorescein was used as a target of free radical attack, with 2,2'-azobis (2-amidinopropane) dihydrochloride as a peroxyl radical generator.

\section{Statistical analysis}

Data are reported as means \pm standard error (SE). Student's paired t test was used to assess differences within groups (baseline and 2-year follow-up) and Kruskall-Wallis test for difference between the groups. Pearson's correlation coefficients were used to express the associations between the variables.

\section{Results}

Glucose homeostasis, aerobic capacity, oxidative stress and its defence mechanisms in subjects with IGT

Baseline and 2-year follow-up values of the IGT subjects $(\mathrm{n}=22)$ are shown in Table 2 . Body weight decreased by $-4.4 \mathrm{~kg}(4.9 \%)(P<0.001)$. In addition, the fasting glucose, 2 -h glucose, $\mathrm{HbA}_{1 \mathrm{c}^{\prime}}$ serum protein carbonyl and uric acid concentrations decreased significantly in the IGT subjects (Table 2). Maximal oxygen uptake variables $\left(\mathrm{VO}_{2 \max }\right.$ and $\mathrm{VO}_{2 \mathrm{max}} /$ weight) and the protein content of GRP75

Table 2: Indices of glucose $m$ etabolism, weight, $m$ axim al oxygen uptake and oxidative stress in the subjects with im paired glucose tolerance (IGT), $\mathbf{n}=\mathbf{2 2}$.

\begin{tabular}{|c|c|c|c|c|}
\hline & Baseline & 2-year follow-up & Change & $P$ value \\
\hline Fp-glucose, $\mathrm{m} \mathrm{mol} / \mathrm{l}$ & $6.0 \pm 0.1$ & $5.8 \pm 0.1$ & $-0.3 \pm 0.1$ & 0.013 \\
\hline 2h-glucose, $\mathrm{m} \mathrm{mol} / \mathrm{l}$ & $7.7 \pm 0.3$ & $6.4 \pm 0.4$ & $-1.2 \pm 0.5$ & 0.013 \\
\hline $\mathrm{HbA}_{\mid c}, \%$ & $5.7 \pm 0.1$ & $5.4 \pm 0.1$ & $-0.4 \pm 0.1$ & $<\left.0.00\right|^{a}$ \\
\hline W eight, kg & $89.7 \pm 1.8$ & $85.3 \pm 2.0$ & $-4.4 \pm 1.1$ & $<0.001$ \\
\hline $\mathrm{BM} I\left(\mathrm{~kg} / \mathrm{m}^{2}\right)$ & $29.9 \pm 0.5$ & $28.4 \pm 0.5$ & $-1.5 \pm 0.4$ & $<0.001$ \\
\hline $\mathrm{VO}_{2 \max }, 1 / \min$ & $2.28 \pm 0.14$ & $2.43 \pm 0.13$ & $0.2 \pm 0.0$ & $<0.001$ \\
\hline $\mathrm{VO}_{2 \max } /$ weight, $\mathrm{ml} / \mathrm{kg} / \mathrm{min}$ & $26.1 \pm 1.6$ & $28.5 \pm 1.5$ & $2.4 \pm 0.6$ & $<0.001$ \\
\hline GRP75 (muscle), arb. u. & $0.95 \pm 0.11$ & $1.28 \pm 0.16$ & $0.33 \pm 0.12$ & 0.014 \\
\hline HSP60 (muscle), arb. u. & $0.35 \pm 0.05$ & $0.56 \pm 0.11$ & $0.21 \pm 0.08$ & 0.022 \\
\hline P. carbonyls (serum), arb. u. & $0.12 \pm 0.00$ & $0.11 \pm 0.00$ & $-0.00 \pm 0.00$ & $0.010^{\mathrm{b}}$ \\
\hline Uric acid, $\mu \mathrm{mol} / \mathrm{l}$ & $375 \pm 12$ & $337 \pm 14$ & $-37 \pm 9$ & 0.001 \\
\hline
\end{tabular}

Data are given as $\mathrm{m}$ eans $\pm \mathrm{SE}$; arb. $\mathrm{u} .=$ arbitrary units, ${ }^{\mathrm{a}} \mathrm{n}=2 \mathrm{I},{ }^{\mathrm{b}} \mathrm{n}=20$ 
and HSP60 increased significantly, compared with the pre-intervention values (Table 2).

\section{Comparison of IGT sub-groups}

At baseline, $\mathrm{HbA}_{1 \mathrm{c}}$ was similar in the IGTslow and IGTfast group, while HOMA-IR was 49\% (1.7 units) higher $(P=$ 0.087 ) in the IGTfast group (Table 3 ). Most of the measured markers of oxidative stress and antioxidative capacity of serum and skeletal muscle were similar between the groups. The serum protein carbonyl concentration was, however $17 \%$ higher in the IGTslow than in the IGTfast group $(P=0.002$, Table 3$)$. The total energy intake and vitamin $\mathrm{C}$ were similar at baseline, but the vitamin $\mathrm{E}$ intake was 34\% (4.2 mg/day) lower in the IGTslow than in the IGTfast group $(P=0.003)$.

During the 2-year intervention, there were no significant changes in the energy intake or vitamin $\mathrm{C}$ in the IGTslow and IGTfast groups. Vitamin E intake was lower in the IGTslow than in the IGTfast group during the whole study period (Figure 1). During the follow-up period, body weight reduced by 5.1 (SD 6.2; range: 0.3 to -9.9) $\mathrm{kg}$ in the IGTfast group and by 3.6 (SD 3.2; range: 3.0 to -14.5 ) kg in the IGTslow group [24]; but the difference between the groups was not statistically significant.

Maximal oxygen uptake variables increased and $\mathrm{HbA}_{1 \mathrm{c}}$ concentrations decreased in both groups but HOMA-IR values decreased only in the IGTfast group (Table 3). Serum concentrations of uric acid decreased significantly in both groups (Table 3 ), but serum protein carbonyl concentrations decreased only in the IGTfast group $(P=$ 0.0213 ). After 2 years, the serum protein carbonyl concentrations were still higher in the IGTslow than in the IGTfast group $(P=0.015)$ (Table 3$)$. The intervention period did not significantly affect the ORAC values in either group (Table 3 ). There were no changes in protein oxidation or lipid peroxidation in the skeletal muscle in either group (Table 3 ).

\section{Chaperone responses}

During the intervention, the expression of mitochondrial HSP60 increased (79\% in the IGTslow and 38\% IGTfast group) significantly in both groups (IGTslow: $P=0.034$ and IGTfast: $P=0.029)$ and GRP75 increased (38\%) significantly in the IGTslow group $(P=0.022)$, while only a tendency was recorded in the IGTfast group $(P=0.072$; Figure 2). On the other hand, no changes were observed in the cytoplasmic chaperones HSP72 or HSP 90 in either of the groups (Figure 3 ).

There were positive correlations between the increase of muscle HSP60 and the increase of the serum ORAC values $(r=0.92 ; P=0.001)$ in the IGTslow group (Figure 4$)$. The improvement of maximal oxygen uptake ( $\mathrm{VO}_{2 \max } /$ weight $)$ correlated negatively with decreased weight $(r=-0.617 ; P$ $=0.033)$ and 2 -h glucose $(r=-0.613 ; P=0.034)$ and the improved $\mathrm{VO}_{2 \max }$ value correlated positively with the increase of protein expression of GRP75 $(r=0.750 ; P=$ $0.005)$ in the IGTfast group and negatively in the IGTslow group $(\mathrm{r}=-0.842 ; \mathrm{P}=0.004)$ (Figure 5).

\section{Discussion}

This is the first study to investigate the HSP responses in human skeletal muscle tissue during a long-term exercisediet intervention. After the intervention period, oxidative stress was reduced as shown by decreased serum levels of uric acid and protein carbonyls, and cytoprotection was improved in the skeletal muscle tissue, observed as the increased expression of mitochondrial HSP60 and GRP75

Table 3: Indices of glucose $m$ etabolism and oxidative stress from serum and skeletal $m$ uscle sam ples, as well as $m$ axim al oxygen uptake in the subjects with im paired glucose tolerance (IGT) divided into two muscle phenotype groups.

\begin{tabular}{|c|c|c|c|c|}
\hline & IGTslow subjects Baseline & 2-year follow-up & IGTfast subjects Baseline & 2-year follow-up \\
\hline$n=($ Female $/$ Male $)$ & $10(4 / 6)$ & & $12(2 / 10)$ & \\
\hline \multicolumn{5}{|l|}{ Serum } \\
\hline $\mathrm{HbA}_{\mathrm{Ic}}, \%$ & $5.74 \pm 0.13$ & $5.38 \pm 0.08 *$ & $5.67 \pm 0.11$ & $5.33 \pm 0.14^{* *}$ \\
\hline HOM A-IR & $3.52 \pm 0.30$ & $3.22 \pm 0.51$ & $5.23 \pm 0.75$ & $3.77 \pm 0.7 I^{*}$ \\
\hline ORAC, $\mu \mathrm{mol}$ & $56.0 \pm 4.5$ & $58.2 \pm 3.1$ & $54.0 \pm 3.4$ & $55.4 \pm 3.2$ \\
\hline P. carbonyl, arb.u. & $0.129 \pm 0.005$ & $0.126 \pm 0.00$ & $0.110 \pm 0.003 \#$ & $0.106 \pm 0.003 * \ldots$ \\
\hline Uric acid, $\mu \mathrm{mol} / \mathrm{l}$ & $370 \pm 17$ & $331 \pm 18^{* *}$ & $379 \pm 17$ & $342 \pm 2 I^{*}$ \\
\hline \multicolumn{5}{|l|}{ Skeletal muscle } \\
\hline P. carbonyl, arb.u. & $0.074 \pm 0.011$ & $0.071 \pm 0.008$ & $0.072 \pm 0.007$ & $0.070 \pm 0.005$ \\
\hline 4-HNE, arb.u. & $0.29 \pm 0.07$ & $0.24 \pm 0.04$ & $0.25 \pm 0.04$ & $0.26 \pm 0.04$ \\
\hline \multicolumn{5}{|l|}{ Maximal oxygen uptake } \\
\hline $\mathrm{VO}_{2 \max }, 1 / \min$ & $1.96 \pm 0.22^{\mathrm{a}}$ & $2.10 \pm 0.20 * \mathrm{a}$ & $2.52 \pm 0.15$ & $2.69 \pm 0.15^{* *}$ \\
\hline $\mathrm{VO}_{2 \max }, /$ weight $\mathrm{ml} / \mathrm{kg} / \mathrm{min}$ & $23.3 \pm 2.7 \mathrm{a}$ & $25.3 \pm 2.4 * \mathrm{a}$ & $28.2 \pm 1.7$ & $30.9 \pm 1.6 * *$ \\
\hline
\end{tabular}

Data are given as means $\pm \mathrm{SE} ; * P<0.05, * * P<0.01$ within group; $\# P<0.05, \# P<0.0$ l between groups; ${ }^{\mathrm{a}} n=9$. 


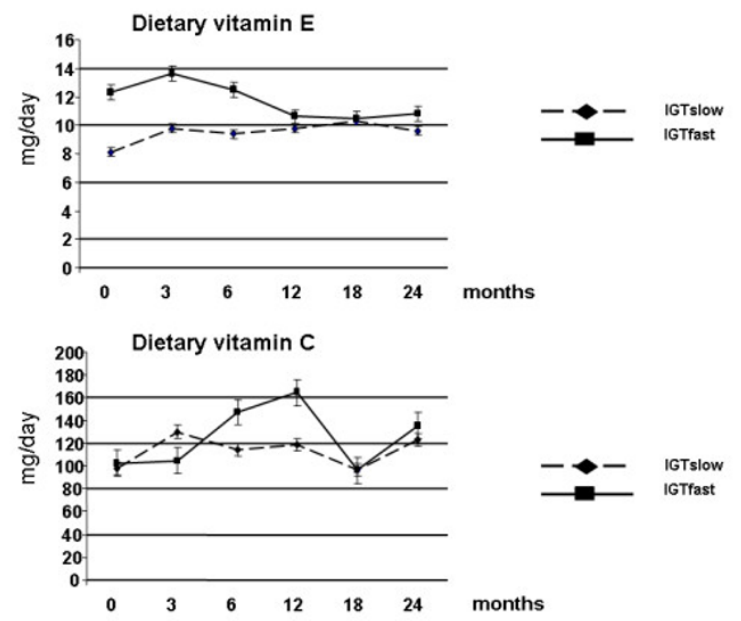

Figure I

Dietary vitamin C and $E$ intakes during a 2-year intervention in subjects with impaired glucose tolerance (IGT), divided into slow $(n=10)$ and fast $(n=$ 12) fibre type sub-groups.

in the IGT subjects while no response was found in cytoplasmic chaperones HSP72 and HSP90.

In this study, we aimed to investigate if the muscle fibre composition is associated with the above improvements, and hence the IGT subjects were into two sub-groups

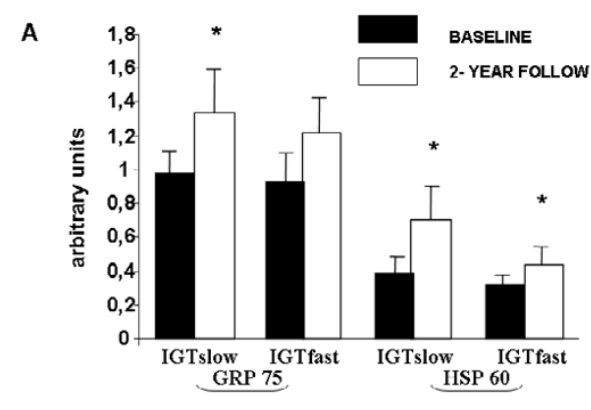

B

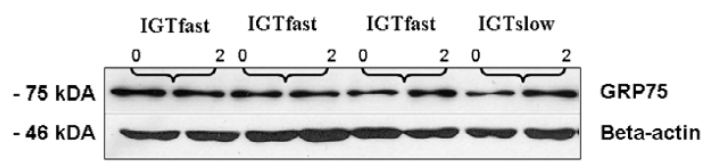

Figure 2

(A) Effects of the 2-year intervention on the protein expression of GRP75 and HSP60 in the vastus lateralis muscle of subjects with impaired glucose tolerance (IGT), divided into slow $(n=10)$ and fast $(n=12)$ fibre type sub-groups. Data are given as means $\pm S E$. $* P<$ 0.05 within groups. (B) Representative Western blots, using anti-GRP75 and beta-actin antibodies, of whole tissue homogenates from skeletal muscle biopsies of four IGT subjects at baseline (0) and after 2-year follow-up (2).
A

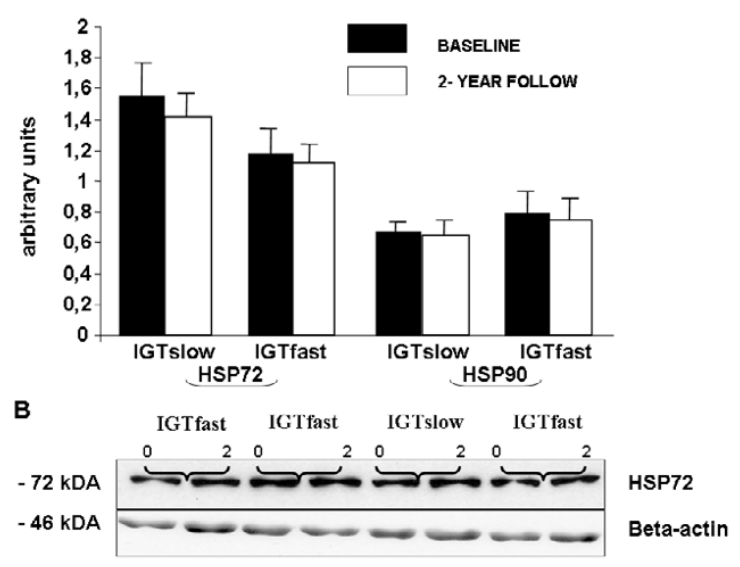

Figure 3

(A) Effects of the 2-year intervention on the protein expression of HSP72 and HSP90 in the vastus lateralis muscle of subjects with impaired glucose tolerance (IGT), divided into slow $(n=10)$ and fast $(n=\mid 2)$ fibre type sub-groups. Data are given as means $\pm S E$. $* P<$ 0.05 within groups. (B) Representative Western blots, using anti-HSP72 and beta-actin antibodies, of whole tissue homogenates from skeletal muscle biopsies of four IGT subjects at baseline (0) and after 2-year follow-up (2).

(IGTfast and IGTslow). In general, men and women have, on an average, $45 \%$ and $55 \%$ of MHC I fibers (slow oxidative fibers) $[40,41]$. In our study, the muscle fibre composition of the two sub-groups differed significantly [24], The fibre type composition remained unchanged in the two subject groups, although the exercise training slightly

Figure 4

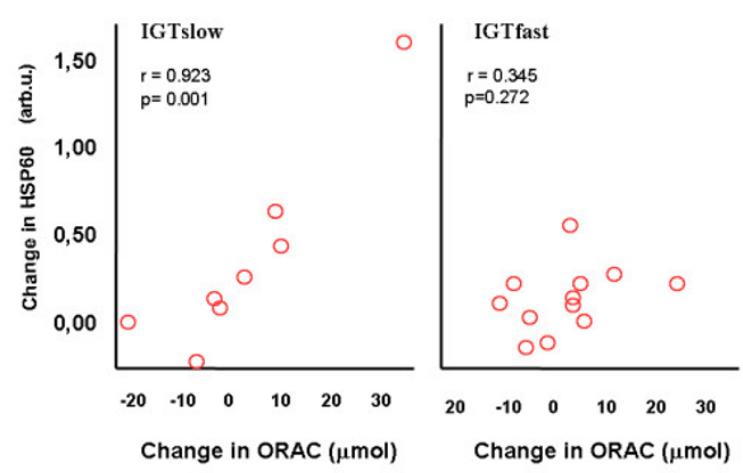

Figure 4

Relationship between the changes of the HSP60 and ORAC values during a 2-year intervention in subjects with impaired glucose tolerance (IGT), divided into slow $(n=8)$ and fast $(n=12)$ fibre type sub-groups. 

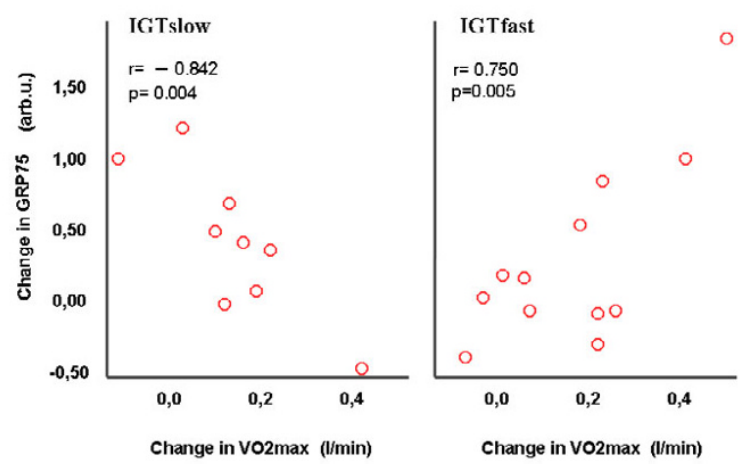

Figure 5

Relationship between the changes of the GRP75 and $\mathrm{VO}_{2 \max }$ values during a 2-year intervention in subjects with impaired glucose tolerance (IGT), divided into slow $(n=9)$ and fast $(n=\mid 2)$ fibre type subgroups.

increased (n.s) the proportion of MHC I and decreased (n.s) the proportion of MHC IIx isoforms in the vastus lateralis muscle in IGTslow group [24]. Otherwise, there were no differences between the sub-groups in physical activity or in dietary intake before or during the intervention, except for vitamin $\mathrm{E}$ intake at baseline.

\section{Chaperones and exercise}

Physical inactivity is one of the major non-genetic determinants of type 2 diabetes. In the present study, the improvement of maximal oxygen uptake in both subgroups shows that the exercise training protocol was effective. Presumably, the increased expression of mitochondrial HSP60 and GRP75 in vastus lateralis muscle in the IGTslow group and that of HSP60 in the IGTfast group were responses to our intervention program. Induced HSP60 and HSP72 expressions in skeletal muscle have also been reported in a short-term exercise intervention in healthy humans $[42,43]$. Consistently, 8 weeks of endurance training increased GRP75 expression in red gastrocnemius muscle of streptozotocin-induced diabetic (SID) rats as well as non-diabetic control rats [2]. In addition, we have recently shown that after four weeks of immobilization, acute intensive non-damaging exercise up-regulated especially HSP60 expression in the plantaris and gastrocnemius muscles in rats [32]. Furthermore, Mattson et al. [44] have reported that both HSP60 and GRP75 are up-regulated in rat skeletal muscle after 8 weeks of endurance training. In those studies, up-regulation of HSP60 and GRP75 was associated with increased skeletal muscle citrate synthase activity (CS) [2,44]. Menshikova et al. [45] have recently shown that a 4 month walking combined with weight-loss increased CS activity $29 \pm 9 \%$ in previously sedentary obese men and women and induced mitochondrial biogenesis in skeletal muscle. Our exercise program also increased CS activity in vastus lateralis muscle in both groups (34\% in the IGTslow and 20\% IGTfast group) [24]. However, we did not find any correlation between increased CS activity and HSP60 or GRP75 expression. On the other hand, the improvement in $\mathrm{VO}_{2 \max }$ correlated positively with increased protein expression of GRP75 in the IGTfast group but not with the weight loss.

Diabetes has been reported to cause mitochondrial dysfunction and attenuated synthesis of a variety of proteins, including HSP60 in mitochondria [46,47]. The skeletal muscle insulin resistance and mitochondrial dysfunction are associated with ageing, type 2 diabetes and in offspring of type 2 diabetes [48]. The reduced oxidative activity could also be a result of a sedentary lifestyle, and no data on correlations between changes in oxidative capacity and insulin sensitivity following exercise in type 2 diabetes have been published [49]. The capacity of HSP60 to stabilize mitochondrial proteins, promote mitochondrial protein biosynthesis and to prevent mitochondrial apoptosis seems to be crucial for its protective function [50]. In the present study, the adaptive changes in the expression of GRP75 and HSP60 could support mitochondrial protein import, protein folding and enhance tissue protection in insulin-resistant muscle tissue. These adaptive changes of mitochondrial HSPs and increased oxidative capacity are mainly due to increased contractile activity of skeletal muscle. However, Civitarese et al. [51] have recently shown in young obese subjects that six months caloric restriction alone, or with exercise reduces DNA damage and increases muscle mitochondrial biogenesis (up regulation of genes involving mitochondrial function) without any increase of oxidative enzymes including CS. Skeletal muscle from obese subjects contains a smaller number of mitochondria because of the lower ratio of type 1 to type 2 muscle fibers and have reduced oxidative capacity [45,52]. Several genes acting in antioxidative processes against oxidative stress are defective in diabetic subjects and correlate with the oxidative capacity $[19,52]$. Exercise activates PGC- $1 \alpha$, which mainly mediates transcriptional regulation of nuclear genes encoding mitochondrial proteins (NGEMP). These nuclear-derived gene products have to import into mitochondria via the protein-import machinery. Imported NGEMPs interact with GRP75, and GRP75 drives translocation of these precursors across the mitochondrial matrix. In an ATP-dependent process precursors are released and bound to the HSP60. Therefore, both GRP75 and HSP60 are essential for mitochondrial function and biogenesis [17]. Also, it has recently been shown that the basal expression of 
HSP72 mRNA in the skeletal muscle is lower in type 2 diabetics, compared with healthy control subjects, which may lead to an imbalance of antioxidant defence mechanism [19].

In the present study, interestingly the expression of the cytoplasmic HSP72 and HSP90 in skeletal muscle was not affected by the exercise-diet intervention in either of the study groups. Most studies showing that exercise induced HSP72 [19], have used low force exercises with continuous activity. However, Gjovaag et al. [53] have shown that high force exercise with intermittent activity like weight training decrease HSP72 expression in very well trained males. In this study, we used similar type of supervised strength and power-type exercise than Gjovaag et al., and it may be one reason why our exercise program did not increase the expression of the HSP72. On the other hand since HSP induction is also dependent on the training levels of the subjects prior to the exercise intervention $[54,55]$, we may not directly compare the responses of the sedentary subjects with very well trained ones.

Furthermore, we aimed to investigate the association of tissue defences with improved glucose metabolism. We found a decrease of the 2-h glucose and $\mathrm{HbA}_{1 \mathrm{c}}$ concentrations in the IGTslow and IGTfast groups and a decrease of the fasting glucose and HOMA-IR values in the IGTfast group [24]. These results also agree with those presented in a meta-analysis by Snowling and Hopkins [56] showing that aerobic, resistance, and combined exercise have small to moderate beneficial effects on glucose metabolism in type 2 diabetic subjects. However, our findings did not correlate with the markers of improved cytoprotection of the skeletal muscle in either group. Fasting values of glucose and insulin (HOMA-IR) are depending on the hepatic glucose control, but not peripheral glucose metabolism. Petersen et al. [57] have show that improvements in basal and insulin-stimulated hepatic glucose metabolism were associated reduction in intrahepatic lipid (IHL) $(P=0.0009)$ without significant changes in insulin-stimulated peripheral glucose uptake after a moderate weight loss ( $8 \%$ of their body weight). The improvement of the $\mathrm{VO}_{2 \max }$ /weight correlated negatively with the 2-h glucose values at the 2-year follow-up in the IGTfast group.

\section{Antioxidant capacity}

In addition to the HSP responses, we studied the antioxidant capacity as measured by ORAC in the serum. ORAC concentrations were slightly increased in both study groups during the intervention but the increase was not statistically significant. In agreement with our results, a combination of antioxidant mixture supplementation and 24 days of cold-weather field training did not significantly affect ORAC or other oxidative stress markers [4]. On the other hand, changes in the serum levels may not always reflect the trainings adaptations gained in skeletal muscle, especially if the samples were taken at rest. We, however, found a significant positive correlation between the increased content of HSP60 and the ORAC values in the IGTslow group. No study has so far been published investigating the association between the ORAC and HSP levels. In studies applying other methods for antioxidant capacity have been used, endurance training contributed to the improved cardiac protection by enhancing the antioxidant capacity and HSP induction $[54,55]$.

No association was found between the improvements in the glucose metabolism and the antioxidant capacity or HSP defence during the intervention, although it has been recently shown that, in type 2 diabetic subjects, insulin resistance correlates with decreased expression of HSP72 in skeletal muscle at mRNA level [6].

\section{Oxidative stress}

Increased production of ROS is typical in type 2 diabetic subjects $[18,58]$. Hyperglycemia decreases glutathione synthesis and impairs the antioxidant defence $[17,59]$. One of the most toxic aldehydes formed during lipid peroxidation is 4-hydroxynonenal (HNE), which can denature proteins and form protein adducts. It has been demonstrated that the induction of HSP72 is closely associated with and regulated by 4 -HNE protein adducts [60]. In the present study, however, we neither observed any differences in the HSP72 expression nor 4-HNE protein adduct levels in the skeletal muscles of the subjects with impaired glucose tolerance. The only previously published study has shown that both long-term exercise training and one week of intensive resistance training resulted in increased 4-HNE, malondialdehyde (MDA) and thiobarbituric acid-reactive substance (TBARS) levels in female weightlifters [61]. The intensity of exercise in the present study was not as high as in the Liu's study [61]. Protein carbonyls have been widely used marker of oxidative modification of proteins. Elevated protein carbonyl levels have been detected both in type 1 and type 2 and also in experimental diabetes $[2,15,62]$. We observed a small, but statistically significant decrease of plasma protein carbonyls after the intervention in the IGTfast group. In agreement with our results, a recent study showed that 14 weeks of training decreased protein carbonyl content and induced HSP60 expression without affecting HSP72 expression in the heart of doxorubicin treated mice [63]. Furthermore, moderate training decreased the protein carbonyl content in rat liver without affecting lipid peroxidation [64].

\section{Conclusion}

To conclude, exercise training combined with dietary counselling improved glucose metabolism and maximal oxygen uptake in subjects with impaired glucose toler- 
ance, regardless of the muscle fibre phenotype. The intervention increased the mitochondrial chaperones in the skeletal muscle, while no changes took place in the cytoplasmic chaperones. The mitochondrial responses in the IGTslow sub-group were slightly greater than in the IGTfast subgroup. The enhancement of mitochondrial HSP defences may reduce glucose toxicity, since muscle mitochondria are important sources of oxygen derived radicals and since insulin resistance and diabetes are associated with increased oxidative stress.

\section{Abbreviations}

DPS: the Finnish Diabetes Prevention Study; GRP75: glucose-regulated protein 75; $\mathrm{HbA}_{1 \mathrm{c}}$ : Hemoglobin A1c; HNE: 4-hydroxynonenal; HOMA-IR: homeostasis model assessment for insulin resistance; HSP: heat shock protein; IGT: impaired glucose tolerance; IHL: intrahepatic lipid; MAPK: mitogen-activated protein kinase; MHC: myosin heavy chain; NGEMP: nuclear genes encoding mitochondrial proteins; ORAC: oxygen radical absorbing capacity; PKB/AKT: protein kinase B; ROS: reactive oxygen species; SID: streptozotocin-induced diabetes TBARS: thiobarbituric acid-reactive substance; $\mathrm{VO}_{2 \max }$ : maximal oxygen uptake.

\section{Competing interests}

The author(s) declare that they have no competing interests.

\section{Authors' contributions}

$\mathrm{HH}, \mathrm{JM}$ and SA were responsible overall design of study. $\mathrm{MV}$, SA, MA and MG were responsible of the analysis of the results and MV and SA for statistical analysis. MG performed most of the biochemical analyses and MA and MV provided technical guidance and advice for biochemical methods. RP was performed MHC analysis. JPH was responsible of taking off muscle biopsies. JL and MR were responsible of dietary intervention and analysis. $\mathrm{KH}, \mathrm{OH}$, and PN critically reviewed the manuscript, with important impact of intellectual content. MV wrote the draft of the manuscript. MA and SA provided the critical revision of the manuscript. All the authors have read and approved the final manuscript.

\section{Acknowledgements}

The authors wish to express their gratitude to Mrs. Minna Glad for excellent technical assistance, to Mrs. Arja Kylliäinen for her assistance in statistical analyses and to Mr. Antti Huuskonen for his editorial assistance. The study was supported by grants from the Research Council for Physical Education and Sports, the Finnish Ministry of Education, the Juho Vainio Foundation, Turku University of Applied Sciences R\&D program and the COST Actions B35 and BM0602. Mika Venojärvi was supported by TULES Graduate School.

\section{References}

I. Petersen KF, Shulman GI: New insights into the pathogenesis of insulin resistance in humans using magnetic resonance spectroscopy. Obesity (Silver Spring) 2006, I 4 Suppl I:34S-40S.

2. Atalay M, Oksala NK, Laaksonen DE, Khanna S, Nakao C, Lappalainen J, Roy S, Hänninen O, Sen CK: Exercise training modulates heat shock protein response in diabetic rats. J Appl Physiol 2004, 97(2):605-6II.

3. Muchova J, Liptakova A, Orszaghova Z, Garaiova I, Tison P, Carsky J, Durackova Z: Antioxidant systems in polymorphonuclear leucocytes of Type 2 diabetes mellitus. Diabet Med 1999, I 6(I):74-78.

4. Parthiban A, Vijayalingam S, Shanmugasundaram KR, Mohan R: Oxidative stress and the development of diabetic complications- antioxidants and lipid peroxidation in erythrocytes and cell membrane. Cell Biol Int 1995, I 9( I 2):987-993.

5. Bukau B, Horwich AL: The Hsp70 and Hsp60 chaperone machines. Cell 1998, 92(3):35I-366.

6. Kurucz I, Morva A, Vaag A, Eriksson KF, Huang X, Groop L, Korany $L$ : Decreased expression of heat shock protein 72 in skeletal muscle of patients with type 2 diabetes correlates with insulin resistance. Diabetes 2002, 5 I(4): I I02-I I09.

7. Kang PJ, Ostermann J, Shilling J, Neupert W, Craig EA, Pfanner N: Requirement for hsp70 in the mitochondrial matrix for translocation and folding of precursor proteins. Nature 1990 , 348(6297): | 37- I43.

8. Martin J, Horwich AL, Hartl FU: Prevention of protein denaturation under heat stress by the chaperonin Hsp60. Science 1992, 258(5084): $995-998$.

9. Basso AD, Solit DB, Chiosis G, Giri B, Tsichlis P, Rosen N: Akt forms an intracellular complex with heat shock protein $\mathbf{9 0}$ (Hsp90) and Cdc37 and is destabilized by inhibitors of $\mathrm{Hsp} 90$ function. J Biol Chem 2002, 277(42):39858-39866.

10. Csermely P, Schnaider T, Soti C, Prohaszka Z, Nardai G: The 90kDa molecular chaperone family: structure, function, and clinical applications. A comprehensive review. Pharmacol Ther 1998, 79(2): I29-168.

II. Liu Y, Steinacker JM: Changes in skeletal muscle heat shock proteins: pathological significance. Front Biosci 200I, 6:DI2-25.

12. Locke M, Noble EG, Atkinson BG: Inducible isoform of HSP70 is constitutively expressed in a muscle fiber type specific pattern. Am J Physiol I99I, 26 I(5 Pt I):C774-9.

13. Ornatsky OI, Connor MK, Hood DA: Expression of stress proteins and mitochondrial chaperonins in chronically stimulated skeletal muscle. Biochem J 1995, 3 I I (I): I I9-I23.

14. Valko M, Leibfritz D, Moncol J, Cronin MT, Mazur M, Telser J: Free radicals and antioxidants in normal physiological functions and human disease. Int J Biochem Cell Biol 2007, 39(I):44-84.

15. Dominguez C, Ruiz E, Gussinye $M$, Carrascosa A: Oxidative stress at onset and in early stages of type I diabetes in children and adolescents. Diabetes Care 1998, 2 I (10): I736-1742.

16. Hotta M, Tashiro F, Ikegami H, Niwa H, Ogihara T, Yodoi J, Miyazaki J: Pancreatic beta cell-specific expression of thioredoxin, an antioxidative and antiapoptotic protein, prevents autoimmune and streptozotocin-induced diabetes. J Exp Med 1998, | 88(8): |445-|45|.

17. Atalay $M$, Laaksonen DE: Diabetes, oxidative stress and physical exercise. J Sport Sci Med 2002, I(I): I-I4.

18. Houstis N, Rosen ED, Lander ES: Reactive oxygen species have a causal role in multiple forms of insulin resistance. Nature 2006, 440(7086):944-948.

19. Bruce CR, Carey AL, Hawley JA, Febbraio MA: Intramuscular heat shock protein 72 and heme oxygenase-I mRNA are reduced in patients with type 2 diabetes: evidence that insulin resistance is associated with a disturbed antioxidant defense mechanism. Diabetes 2003, 52(9):2338-2345.

20. Eriksson J, Lindström J, Valle T, Aunola $S$, Hämäläinen $H$, llanneParikka P, Keinänen-Kiukaanniemi S, Laakso $M$, Lauhkonen $M$, Lehto $P$, Lehtonen A, Louheranta A, Mannelin M, Martikkala V, Rastas M, Sundvall J, Turpeinen A, Viljanen T, Uusitupa M, Tuomilehto J: Prevention of Type II diabetes in subjects with impaired glucose tolerance: the Diabetes Prevention Study (DPS) in Finland. Study design and I-year interim report on the feasibility of the lifestyle intervention programme. Diabetologia 1999, 42(7):793-80I. 
2I. Tuomilehto J, Lindström J, Eriksson JG, Valle TT, Hämäläinen $H$, llanne-Parikka $P$, Keinänen-Kiukaanniemi S, Laakso $M$, Louheranta $A$, Rastas M, Salminen V, Uusitupa M: Prevention of type 2 diabetes mellitus by changes in lifestyle among subjects with impaired glucose tolerance. N Engl J Med 200I, 344(I 8): I 343-I350.

22. Lindström J, Louheranta A, Mannelin M, Rastas M, Salminen V, Eriksson J, Uusitupa M, Tuomilehto J: The Finnish Diabetes Prevention Study (DPS): Lifestyle intervention and 3-year results on diet and physical activity. Diabetes Care 2003 26(I 2):3230-3236.

23. World Health Organization: World Health Organization: Diabetes mellitus. In Report of a WHO Study Group. Techical Report Series No 727 Geneva ; 1985.

24. Venojärvi M, Puhke R, Hämäläinen $H$, Marniemi J, Rastas $M$, Rusko $H$, Nuutila P, Hänninen $O$, Aunola S: Role of skeletal muscle-fibre type in regulation of glucose metabolism in middle-aged subjects with impaired glucose tolerance during a long-term exercise and dietary intervention. Diabetes Obes Metab 2005 7(6):745-754

25. Henriksson KG: "Semi-open" muscle biopsy technique. A simple outpatient procedure. Acta Neurol Scand 1979 59(6):317-323.

26. Aunola S, Marniemi J, Alanen E, Mäntylä M, Saraste M, Rusko H: Muscle metabolic profile and oxygen transport capacity as determinants of aerobic and anaerobic thresholds. Eur J Appl Physio Occup Physiol 1988, 57(6):726-734.

27. Surakka J, Alanen E, Aunola S, Karppi SL, Pekkarinen H: Effects of external light loading in power-type strength training on muscle power of the lower extremities in middle-aged subjects. Int J Sports Med 2006, 27(6):448-455.

28. Ovaskainen ML, Valsta LM, Lauronen J: The compilation of food analysis values as a database for dietary studies - The Finnish experience. Food Chemistry 1996, 57(I): I33-136.

29. Haapa E, Toponen T, Pietinen P, Räsänen L: Annoskuvakirja. Helsinki , Painokaari Oy.; 1985.

30. Pietinen P, Hartman AM, Haapa E, Räsanen L, Haapakoski J, Palmgren J, Albanes D, Virtamo J, Huttunen JK: Reproducibility and validity of dietary assessment instruments. I. A self-administered food use questionnaire with a portion size picture booklet. Am J Epidemiol 1988, I 28(3):655-666.

31. Hämäläinen N, Pette D: Slow-to-fast transitions in myosin expression of rat soleus muscle by phasic high-frequency stimulation. FEBS Lett 1996, 399(3):220-222

32. Venojärvi M, Kvist M, Jozsa L, Kalimo H, Hänninen O, Atalay M: Skeletal muscle HSP expression in response to immobilization and remobilization. Int / Sports Med 2007, 28(4):28I-286.

33. Buss H, Chan TP, Sluis KB, Domigan NM, Winterbourn CC: Protein carbonyl measurement by a sensitive ELISA method. Free Radic Biol Med 1997, 23(3):36l-366

34. Oksala NK, Laaksonen DE, Lappalainen J, Khanna S, Nakao C, Hänninen $\mathrm{O}$, Sen CK, Atalay M: Heat shock protein 60 response to exercise in diabetes: effects of alpha-lipoic acid supplementation. I Diabetes Complications 2006, 20(4):257-26I.

35. Levine RL, Garland D, Oliver CN, Amici A, Climent I, Lenz AG, Ahn BW, Shaltiel S, Stadtman ER: Determination of carbonyl content in oxidatively modified proteins. Methods Enzymol 1990 I 86:464-478.

36. Matthews DR, Hosker JP, Rudenski AS, Naylor BA, Treacher DF Turner RC: Homeostasis model assessment: insulin resistance and beta-cell function from fasting plasma glucose and insulin concentrations in man. Diabetologia 1985, 28(7):4I 2-419.

37. Musser AW, Ortigoza C: Automated determination of uric acid by the hydroxylamine method. Tech Bull Regist Med Technol 1966, 36(2):21-25.

38. Kinnunen $S$, Hyyppä $S$, Lehmuskero A, Oksala N, Mäenpää $P$, Hänninen $O$, Atalay $M$ : Oxygen radical absorbance capacity (ORAC) and exercise-induced oxidative stress in trotters. Eur I App Physiol 2005, 95(5-6):550-556

39. Prior RL, Cao G: In vivo total antioxidant capacity: comparison of different analytical methods. Free Radic Biol Med I999, 27(I I. I 2): I |73-I |8|.

40. Mahon M, Toman A, Willan PL, Bagnall KM: Variability of histochemical and morphometric data from needle biopsy specimens of human quadriceps femoris muscle. J Neurol Sci 1984 63(I):85-100.
4I. Staron RS, Hagerman FC, Hikida RS, Murray TF, Hostler DP, Crill MT, Ragg KE, Toma K: Fiber type composition of the vastus lateralis muscle of young men and women. I Histochem Cytochem 2000, 48(5):623-629.

42. Khassaf M, Child RB, McArdle A, Brodie DA, Esanu C, Jackson MJ: Time course of responses of human skeletal muscle to oxidative stress induced by nondamaging exercise. I Appl Physiol 2001, 90(3): $1031-1035$

43. Morton JP, MacLaren DP, Cable NT, Bongers T, Griffiths RD, Campbell IT, Evans L, Kayani A, McArdle A, Drust B: Time course and differential responses of the major heat shock protein families in human skeletal muscle following acute nondamaging treadmill exercise. J Appl Physiol 2006, I 0 I (I): I 76-I82.

44. Mattson JP, Ross CR, Kilgore JL, Musch TI: Induction of mitochondrial stress proteins following treadmill running. Med $\mathrm{Sc}$ Sports Exerc 2000, 32(2):365-369.

45. Menshikova EV, Ritov VB, Ferrell RE, Azuma K, Goodpaster BH, Kelley DE: Characteristics of Skeletal Muscle Mitochondrial Biogenesis Induced by Moderate-Intensity Exercise and Weight Loss in Obesity. J Appl Physiol 2007, I 03(I):2 I-27.

46. Mokhtar N, Lavoie JP, Rousseau-Migneron S, Nadeau A: Physical training reverses defect in mitochondrial energy production in heart of chronically diabetic rats. Diabetes 1993 , 42(5):682-687

47. Turko IV, Murad F: Quantitative protein profiling in heart mitochondria from diabetic rats. I Biol Chem 2003, 278(37):35844-35849.

48. Sreekumar R, Sreekumaran Nair K: Skeletal muscle mitochondrial dysfunction \& diabetes. Indian J Med Res 2007, I 25(3):399-4 I0.

49. Rabol R, Boushel R, Dela F: Mitochondrial oxidative function and type 2 diabetes. Appl Physiol Nutr Metab 2006, 3 I (6):675-683.

50. Gupta S, Knowlton AA: HSP60, Bax, apoptosis and the heart. Cell Mol Med 2005, 9(I):5I-58.

5I. Civitarese AE, Carling S, Heilbronn LK, Hulver MH, Ukropcova B, Deutsch WA, Smith SR, Ravussin E: Calorie Restriction Increases Muscle Mitochondrial Biogenesis in Healthy Humans. PLoS Med 2007, 4(3):e76.

52. Sell H, Dietze-Schroeder D, Eckel J: The adipocyte-myocyte axis in insulin resistance. Trends Endocrinol Metab 2006 , I 7( 10$)$ :4 I 6-422.

53. Gjovaag TF, Vikne H, Dahl HA: Effect of concentric or eccentric weight training on the expression of heat shock proteins in m. biceps brachii of very well trained males. Eur J Appl Physiol 2006, 96(4):355-362

54. Hamilton KL, Staib JL, Phillips T, Hess A, Lennon SL, Powers SK: Exercise, antioxidants, and HSP72: protection against myocardial ischemia/reperfusion. Free Radic Biol Med 2003, 34(7):800-809

55. Powers SK, Quindry J, Hamilton K: Aging, exercise, and cardioprotection. Ann N Y Acad Sci 2004, I 0 I 9:462-470.

56. Snowling NJ, Hopkins WG: Effects of different modes of exercise training on glucose control and risk factors for complications in type $\mathbf{2}$ diabetic patients: a meta-analysis. Diabetes Care 2006, 29( I I ):25 I8-2527.

57. Petersen KF, Dufour S, Befroy D, Lehrke M, Hendler RE, Shulman GI: Reversal of nonalcoholic hepatic steatosis, hepatic insulin resistance, and hyperglycemia by moderate weight reduction in patients with type 2 diabetes. Diabetes 2005 54(3):603-608

58. Paolisso G, D'Amore A, Volpe C, Balbi V, Saccomanno F, Galzerano $D$, Giugliano D, Varricchio M, D'Onofrio F: Evidence for a relationship between oxidative stress and insulin action in noninsulin-dependent (type II) diabetic patients. Metabolism 1994 43(I I): |426-|429.

59. Laaksonen DE, Atalay M, Niskanen L, Uusitupa M, Hänninen O, Sen CK: Increased resting and exercise-induced oxidative stress in young IDDM men. Diabetes Care 1996, I9(6):569-574.

60. Hamilton RF Jr., Hazbun ME, Jumper CA, Eschenbacher WL, Holian A: 4-Hydroxynonenal mimics ozone-induced modulation of macrophage function ex vivo. Am J Respir Cell Mol Biol 1996, I 5(2):275-282

6I. Liu JF, Chang WY, Chan KH, Tsai WY, Lin CL, Hsu MC: Blood lipid peroxides and muscle damage increased following intensive resistance training of female weightlifters. Ann $N$ Y Acad Sci $2005,1042 \cdot 255-261$ 
62. Cakatay U, Telci A, Salman S, Satman L, Sivas A: Oxidative protein damage in type I diabetic patients with and without complications. Endocr Res 2000, 26(3):365-379.

63. Ascensao A, Magalhaes J, Soares J, Ferreira R, Neuparth M, Marques $\mathrm{F}$, Oliveira J, Duarte J: Endurance training attenuates doxorubicin-induced cardiac oxidative damage in mice. Int J Cardiol 2005, I 00(3):45I-460.

64. Ogonovszky H, Sasvari M, Dosek A, Berkes I, Kaneko T, Tahara S, Nakamoto H, Goto S, Radak Z: The effects of moderate, strenuous, and overtraining on oxidative stress markers and DNA repair in rat liver. Can J Appl Physiol 2005, 30(2): I 86- I 95.

\section{Pre-publication history}

The pre-publication history for this paper can be accessed here:

http://www.biomedcentral.com/1472-6823/8/3/prepub

Publish with Biomed Central and every scientist can read your work free of charge

"BioMed Central will be the most significant development for disseminating the results of biomedical research in our lifetime. "

Sir Paul Nurse, Cancer Research UK

Your research papers will be:

- available free of charge to the entire biomedical community

- peer reviewed and published immediately upon acceptance

- cited in PubMed and archived on PubMed Central

- yours - you keep the copyright

Submit your manuscript here:

http://www.biomedcentral.com/info/publishing_adv.asp
BioMedcentral 